\title{
Complex organic molecules in comets C/2012 F6 (Lemmon) and C/2013 R1 (Lovejoy): detection of ethylene glycol and formamide ${ }^{\star, \star \star, \star \star \star}$
}

\author{
N. Biver ${ }^{1}$, D. Bockelée-Morvan ${ }^{1}$, V. Debout ${ }^{1}$, J. Crovisier ${ }^{1}$, J. Boissier ${ }^{2}$, D. C. Lis ${ }^{3,4}$, N. Dello Russo ${ }^{5}$, R. Moreno ${ }^{1}$, \\ P. Colom ${ }^{1}$, G. Paubert ${ }^{6}$, R. Vervack ${ }^{5}$, and H. A. Weaver ${ }^{5}$ \\ 1 LESIA, Observatoire de Paris, CNRS, UPMC, Université Paris-Diderot, 5 place Jules Janssen, 92195 Meudon, France \\ 2 IRAM, 300 rue de la Piscine, 38406 Saint Martin d'Hères, France \\ 3 California Institute of Technology, Cahill Center for Astronomy and Astrophysics 301-17, Pasadena CA 91125, USA \\ ${ }^{4}$ Sorbonne Universités, UPMC, CNRS, Observatoire de Paris, LERMA, 75014 Paris, France \\ 5 JHU/APL, Laurel, Maryland, USA \\ ${ }^{6}$ IRAM, Avd. Divina Pastora, 7, 18012 Granada, Spain
}

Received 27 March 2014 / Accepted 23 May 2014

\section{ABSTRACT}

\begin{abstract}
A spectral survey in the $1 \mathrm{~mm}$ wavelength range was undertaken in the long-period comets C/2012 F6 (Lemmon) and C/2013 R1 (Lovejoy) using the $30 \mathrm{~m}$ telescope of the Ins titut de radioastronomie millimétrique (IRAM) in April and November-December 2013. We report the detection of ethylene glycol $\left(\mathrm{CH}_{2} \mathrm{OH}\right)_{2}\left(a G g\right.$ ' conformer) and formamide $\left(\mathrm{NH}_{2} \mathrm{CHO}\right)$ in the two comets. The abundances relative to water of ethylene glycol and formamide are $0.2-0.3 \%$ and $0.02 \%$ in the two comets, similar to the values measured in comet $\mathrm{C} / 1995 \mathrm{O} 1$ (Hale-Bopp). We also report the detection of $\mathrm{HCOOH}$ and $\mathrm{CH}_{3} \mathrm{CHO}$ in comet $\mathrm{C} / 2013 \mathrm{R} 1$ (Lovejoy), and a search for other complex species (methyl formate, glycolaldehyde).
\end{abstract}

Key words. astrobiology - astrochemistry - comets: individual: C/2012 F6 (Lemmon) - comets: individual: C/2013 R1 (Lovejoy) radio lines: planetary systems - submillimeter: planetary systems

\section{Introduction}

Comets are the most pristine remnants of the formation of the solar system 4.6 billion years ago. Investigating the composition of cometary nuclei ices provides clues to the physical conditions and chemical processes at play in the primitive solar nebula. Comets may also have played a role in the delivery of water and organic material to the early Earth (Hartogh et al. 2011).

The recent years have seen significant improvement in the sensitivity and spectral coverage of millimetre receivers. The EMIR receivers (Carter et al. 2012) at the Institut de RadioAstronomie Millimétrique (IRAM) are equipped with a fast Fourier-transform spectrometer that offers a wide frequency coverage at a high spectral resolution $(0.2 \mathrm{MHz})$. The combination enables sensitive spectral surveys of cometary atmospheres and searches for complex molecules through their multiple rotational lines in the $1 \mathrm{~mm}$ band.

We report here the detection of ethylene glycol $\left(\mathrm{CH}_{2} \mathrm{OH}\right)_{2}$ and formamide $\left(\mathrm{NH}_{2} \mathrm{CHO}\right)$ in comets $\mathrm{C} / 2012 \mathrm{~F} 6$ (Lemmon) (hereafter referred to as Lemmon) and C/2013 R1 (Lovejoy) (hereafter Lovejoy), for the first time since their discovery in comet C/1995 O1 (Hale-Bopp) (Crovisier et al. 2004a; Bockelée-Morvan et al. 2000). We also present the detection of

\footnotetext{
* Based on observations carried out with the IRAM $30 \mathrm{~m}$ telescope IRAM is supported by INSU/CNRS (France), MPG (Germany) and IGN (Spain).

$\star \star$ Tables 4 and 5 are available in electronic form at http://wwW . aanda.org

$\star \star \star$ The IRAM dataset is available at the CDS via anonymous ftp to cdsarc.u-strasbg.fr (130.79.128.5) or via http://cdsarc.u-strasbg.fr/viz-bin/qcat?]/A+A/566/L5
}

$\mathrm{CH}_{3} \mathrm{CHO}$ and $\mathrm{HCOOH}$ in comet Lovejoy. Comet Lemmon is a long-period comet (initial orbital period of $9800 \mathrm{yr}$; Williams 2014), which reached perihelion at $0.731 \mathrm{AU}$ on 24 March 2013. Comet Lovejoy passed perihelion on 22 December 2013 at $0.812 \mathrm{AU}$ from the Sun and also is a high-inclination long-period comet originating from the Oort Cloud (initial orbital period of $7000 \mathrm{yr}$; Williams 2014). Comets Lemmon and Lovejoy became unexpectedly bright naked-eye comets, reaching visual magnitudes of 4.5 and 4.8 , and displayed high water production rates near perihelion of $1 \times 10^{30}$ and $1.5 \times 10^{29}$ molec. $\mathrm{s}^{-1}$ (Combi et al. 2014; Crovisier et al., priv. comm.).

\section{Observations}

Data on comet Lemmon were acquired with the IRAM $30 \mathrm{~m}$ telescope on March 14-18 and April 6-8, 2013, when favourable weather conditions enabled observations. Although one of the most productive comets of the past years, comet Lemmon was relatively far from Earth near perihelion $(\Delta=1.5 \mathrm{AU})$.

Comet Lovejoy was discovered on 7 September 2013 (Lovejoy 2013), which was two and a half months before its optimal observing conditions around perigee at $\Delta=$ $0.397 \mathrm{AU}$ on 19 November. It was observed during three periods: 8-12 November, 27 November-1 December, and 9-16 December 2013, under average to good weather conditions. Additional observations obtained on November 13 and 16 , which focused on the search for phosphine, were reported by Agúndez et al. (2014). During this period, the water production rate of comet Lovejoy increased from $\sim 5$ to $\sim 11 \times$ $10^{28}$ molec. $\mathrm{s}^{-1}$ according to Nançay $\mathrm{OH}$ observations (Crovisier et al., priv. comm.). The best sensitivity was reached at the end 
Table 1. Observing circumstances and reference parameters.

\begin{tabular}{|c|c|c|c|c|c|c|c|}
\hline $\begin{array}{l}\text { UT date } \\
\text { (aaaa/mm/dd.d-dd.d) }\end{array}$ & $\begin{array}{l}\left\langle r_{\mathrm{h}}\right\rangle \\
(\mathrm{AU}) \\
\end{array}$ & $\begin{array}{l}\langle\Delta\rangle \\
(\mathrm{AU}) \\
\end{array}$ & $\begin{array}{c}v_{\exp } \\
\left(\mathrm{km} \mathrm{s}^{-1}\right)\end{array}$ & $\begin{array}{l}T_{\text {kin }} \\
(\mathrm{K})\end{array}$ & $\begin{array}{c}Q_{\mathrm{H}_{2} \mathrm{O}} \\
\text { (molec. } \mathrm{s}^{-1} \text { ) }\end{array}$ & $\begin{array}{c}Q_{\mathrm{HCN}} \\
\left(\text { molec. s }{ }^{-1}\right)\end{array}$ & $\begin{array}{c}Q_{\mathrm{CH}_{3} \mathrm{OH}} \\
\left(\text { molec. } \mathrm{s}^{-1}\right)\end{array}$ \\
\hline \multicolumn{8}{|c|}{ Comet C/2012 F6 (Lemmon): } \\
\hline 2013/04/06.4-08.6 & 0.78 & 1.60 & 1.00 & 100 & $\sim 9 \times 10^{29 a}$ & $12.7 \pm 0.9 \times 10^{26}$ & $14.6 \pm 1.1 \times 10^{27}$ \\
\hline \multicolumn{8}{|c|}{ Comet C/2013 R1 (Lovejoy): } \\
\hline 2013/11/08.2-12.4 & 1.13 & 0.47 & 0.76 & 55 & $0.5 \times 10^{29 b}$ & $7.4 \pm 0.1 \times 10^{25}$ & $1.4 \pm 0.1 \times 10^{27}$ \\
\hline $2013 / 11 / 27.5-31.6$ & 0.92 & 0.47 & 0.90 & 65 & $0.8 \times 10^{29 b}$ & $12.7 \pm 0.1 \times 10^{25}$ & $2.2 \pm 0.2 \times 10^{27}$ \\
\hline 2013/12/09.5-16.6 & 0.83 & 0.71 & 0.93 & 80 & $1.1 \times 10^{29 b}$ & $18.0 \pm 0.1 \times 10^{25}$ & $2.9 \pm 0.2 \times 10^{27}$ \\
\hline
\end{tabular}

Notes. ${ }^{(a)}$ From Combi et al. (2014) and in agreement with $Q_{\mathrm{CH}_{3} \mathrm{OH}}$, and the values of $Q_{\mathrm{H}_{2} \mathrm{O}}$ and $Q_{\mathrm{CH}_{3} \mathrm{OH}} / Q_{\mathrm{H}_{2} \mathrm{O}}$ measured by Paganini et al. (2014). (b) From contemporaneous Nançay OH observations (Crovisier et al., priv. comm.).

of November when the comet was still close to Earth and more active than two weeks earlier.

For the two comets, we surveyed most of the $1 \mathrm{~mm}$ band from 210 to $272 \mathrm{GHz}$ with five different double-sideband tunings. Each tuning covers $2 \times 8 \mathrm{GHz}$ in two linear polarizations, with the upper $8 \mathrm{GHz}$ sideband separated by $8 \mathrm{GHz}$ from the lower sideband. The $166-170 \mathrm{GHz}$ range was also observed in both comets. The comets were tracked with the latest available orbital elements, pointing was checked once every $1-2 \mathrm{~h}$, and residual pointing offsets were estimated from coarse maps of the strongest cometary lines. The HCN J(3-2) line at $265.886 \mathrm{GHz}$ and methanol lines present in all tuning setups were observed regularly to monitor the activity and track the location of the peak of gas emissions in the coma. Table 1 provides the geometric circumstances of the observations together with reference coma and outgassing parameters derived from observations.

\section{Data analysis}

Spectra were corrected for the main beam efficiency $(0.55$ to 0.44 in the $210-272 \mathrm{GHz}$ range). Calibration was regularly checked on reference line sources (W3OH, W51D and IRC +10216$)$ and the main beam efficiency was checked several times per day on planets (e.g., Mars, Uranus). Losses due to bad focus (up to $20 \%$ during some daytime observations) and elevation dependence of the antenna gain were corrected. The beam size varies between $11.7^{\prime \prime}$ and 9.1" from 210 to $272 \mathrm{GHz}$, which corresponds to $\approx 12000$ and $3000-6000 \mathrm{~km}$ at the distances of comets Lemmon and Lovejoy.

Several individual lines of "classical" molecules such as $\mathrm{HCN}, \mathrm{HNC}, \mathrm{CH}_{3} \mathrm{CN}, \mathrm{CH}_{3} \mathrm{OH}, \mathrm{H}_{2} \mathrm{CO}, \mathrm{CS}$, and $\mathrm{H}_{2} \mathrm{~S}$ (and $\mathrm{CO}$ in Lovejoy) were clearly detected (Biver et al. 2013; Agúndez et al. 2014). To search for molecules with weak signatures, we averaged the multiple lines present in the covered frequency range, focusing on the strongest lines with similar expected intensities. As far as possible, only lines for which the noise level was similar were considered. Intensities were computed following the models of Biver et al. (1999, 2000, 2006, 2011), using the coma temperatures and velocities given in Table 1. For comet Lemmon, the 240-272 GHz range was much less noisy, while most of the 210-272 GHz range could be used for Lovejoy. Several molecules previously identified in a few comets were detected using this method, e.g., $\mathrm{HNCO}, \mathrm{OCS}, \mathrm{HC}_{3} \mathrm{~N}$, SO, and $\mathrm{SO}_{2}$ in comet Lemmon, and $\mathrm{HNCO}$ and $\mathrm{HC}_{3} \mathrm{~N}$ in comet Lovejoy (e.g., Biver et al. 2013, and in prep.).

Here, we focus on the detection of ethylene glycol $\left(\mathrm{CH}_{2} \mathrm{OH}\right)_{2}$ in its lowest energy conformer $a G g$ ', and of formamide $\left(\mathrm{NH}_{2} \mathrm{CHO}\right)$ in the two comets. Spectra showing the average of 5 to 13 lines are shown in Figs. 1-2. Table 2 lists average line intensities and inferred production rates. The detailed information on the lines considered in the analysis is

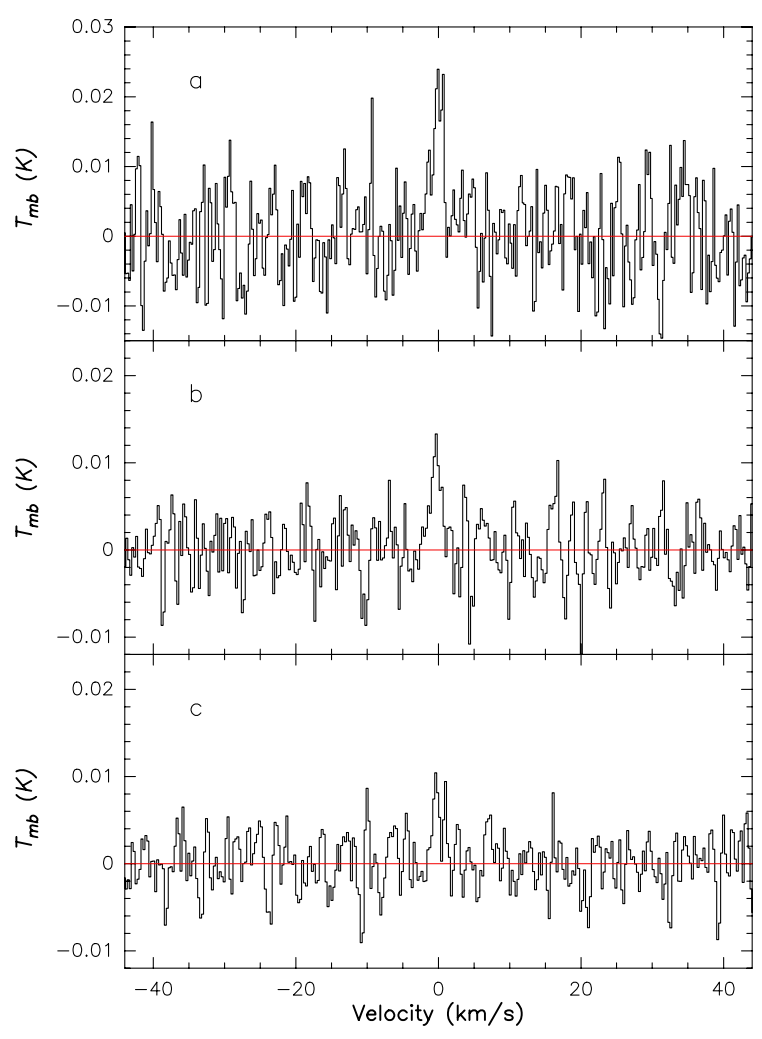

Fig. 1. Weighted average of the 9-13 strongest $a G^{\prime}\left(\mathrm{CH}_{2} \mathrm{OH}\right)_{2}$ lines observed in the 213-272 GHz range (Table 4): a) C/2012 F6 (Lemmon), 6-8 April 2013, b) C/2013 R1 (Lovejoy), 27 Nov.-1 Dec. 2013; c) Lovejoy, 9-16 Dec. 2013. The vertical scale is the main beam brightness temperature and the horizontal scale is the Doppler velocity in the comet frame.

given in Tables 4-5. Excitation processes considered in calculating the production rates of these two molecules are collisional excitation (with neutrals and electrons) and spontaneous decay. Infrared pumping by Sun radiation is not considered because band strengths are not available in the literature. Generally, infrared pumping tends to decrease the effect of spontaneous radiative decay, but for the present observations the difference with full LTE is very small.

The gas kinetic temperature (Table 1) was estimated from the series of methanol rotational lines around $251 \mathrm{GHz}$ : 18 lines sampling energy levels with $E_{\text {up }}$ between 60 and $240 \mathrm{~K}$, and 28 lines with $E_{\text {up }}$ in the range $60-360 \mathrm{~K}$ were detected in comets Lovejoy and Lemmon. The retrieved kinetic temperatures do not differ significantly (by more than $10 \%$ ), whether derived from other series of methanol lines observed between 165 and $305 \mathrm{GHz}$, from methanol lines at offset positions $\left(\approx 7^{\prime \prime}\right)$, or from other molecules $\left(\mathrm{H}_{2} \mathrm{~S}, \mathrm{CS}\right)$. Values derived from $251 \mathrm{GHz}$ and 
Table 2. Average line intensities and production rates of ethylene glycol, formamide, acetaldehyde, and formic acid.

\begin{tabular}{|c|c|c|c|c|c|c|c|c|c|c|}
\hline \multirow[t]{2}{*}{ Molecule } & \multirow{2}{*}{$\begin{array}{l}\text { Freq. } \\
\text { range } \\
(\mathrm{GHz})\end{array}$} & \multirow[t]{2}{*}{ Lines $^{a}$} & \multicolumn{2}{|c|}{$\frac{\text { C/2012 F6 (Lemmon) }}{\text { 6-8 Apr. }}$} & \multicolumn{6}{|c|}{ C/2013 R1 (Lovejoy) } \\
\hline & & & $\begin{array}{c}I^{b-6-\delta} \\
\left(\mathrm{mK} \mathrm{km} \mathrm{s}^{-}\right. \\
\end{array}$ & $\begin{array}{l}Q \\
\text { pr. } \\
\left.10^{26} \mathrm{~s}^{-1}\right)\end{array}$ & $\begin{array}{c}\quad 8-12 \\
I^{b} \\
\left(\mathrm{mK} \mathrm{km} \mathrm{s}^{-}\right. \\
\end{array}$ & $\begin{array}{c}\text { Nov. } \\
Q \\
\left(10^{26} \mathrm{~s}^{-1}\right) \\
\end{array}$ & $\begin{array}{c}27-3 \\
I^{b} \\
\left(\mathrm{mK} \mathrm{km} \mathrm{s}^{-}\right. \\
\end{array}$ & $\begin{array}{c}\text { Nov. } \\
Q \\
\left.{ }^{1}\right)\left(10^{26} \mathrm{~s}^{-1}\right)\end{array}$ & $\begin{array}{c}9^{9-1} \\
I^{b} \\
(\mathrm{mK} \mathrm{km} \mathrm{s} \\
\end{array}$ & $\begin{array}{l}\text { Dec. } \\
Q \\
\left.{ }^{1}\right)\left(10^{26} \mathrm{~s}^{-1}\right)\end{array}$ \\
\hline$\left(\mathrm{CH}_{2} \mathrm{OH}\right)_{2}$ & $213-241$ & $7\left(6^{c}\right)$ & - & - & $<42$ & $<5.3$ & $18 \pm 6$ & $2.5 \pm 0.8$ & $18 \pm 4$ & $3.8 \pm 0.8$ \\
\hline$\left(\mathrm{CH}_{2} \mathrm{OH}\right)_{2}$ & $241-270$ & 9 & $39 \pm 5$ & $22 \pm 3$ & - & - & - & - & - & - \\
\hline$\left(\mathrm{CH}_{2} \mathrm{OH}\right)_{2}$ & $245-268$ & 6 & - & - & $<21$ & $<3.9$ & $23 \pm 4$ & $4.0 \pm 0.7$ & $13 \pm 4$ & $3.0 \pm 0.9$ \\
\hline $\mathrm{NH}_{2} \mathrm{CHO}$ & $223-240$ & 5 & - & - & $<32$ & $<6.4$ & $38 \pm 12$ & $3.2 \pm 1.0$ & $17 \pm 5$ & $3.1 \pm 0.9$ \\
\hline $\mathrm{NH}_{2} \mathrm{CHO}$ & $243-261$ & 5 & $24 \pm 7$ & $15 \pm 4$ & $34 \pm 8$ & $2.2 \pm 0.5$ & $21 \pm 4$ & $1.7 \pm 0.3$ & $16 \pm 5$ & $2.4 \pm 0.7$ \\
\hline $\mathrm{NH}$ & $263-267$ & 2 & $<54$ & $<28$ & $<42$ & $<2.6$ & $22 \pm 8$ & $1.7 \pm 0.6$ & $<24$ & $<3.4$ \\
\hline $\mathrm{CH}_{3} \mathrm{CHO}$ & $242-271$ & 26 & $9 \pm 4$ & $<7$ & - & - & - & - & - & - \\
\hline $\mathrm{CH}_{3} \mathrm{CHO}$ & $211-268$ & $45\left(39^{c}\right)$ & - & - & $<9$ & $<0.7$ & $9 \pm 2$ & $0.8 \pm 0.2$ & $7 \pm 2$ & $1.1 \pm 0.3$ \\
\hline & $241-268$ & 6 & $<24$ & $<6.0$ & - & - & - & - & - & - \\
\hline $\mathrm{HCOOH}$ & $215-271$ & $20\left(16^{c}\right)$ & - & - & $12 \pm 5$ & $<0.6$ & $25 \pm 3$ & $1.3 \pm 0.2$ & $10 \pm 2$ & $1.0 \pm 0.2$ \\
\hline
\end{tabular}

Notes. ${ }^{(a)}$ Number of lines - details are provided in Tables 4-5. ${ }^{(b)}$ Weighted average of line integrated intensities $\int T_{m b} \mathrm{~d} v{ }^{(c)}$ For the $27-31$ Nov. period.

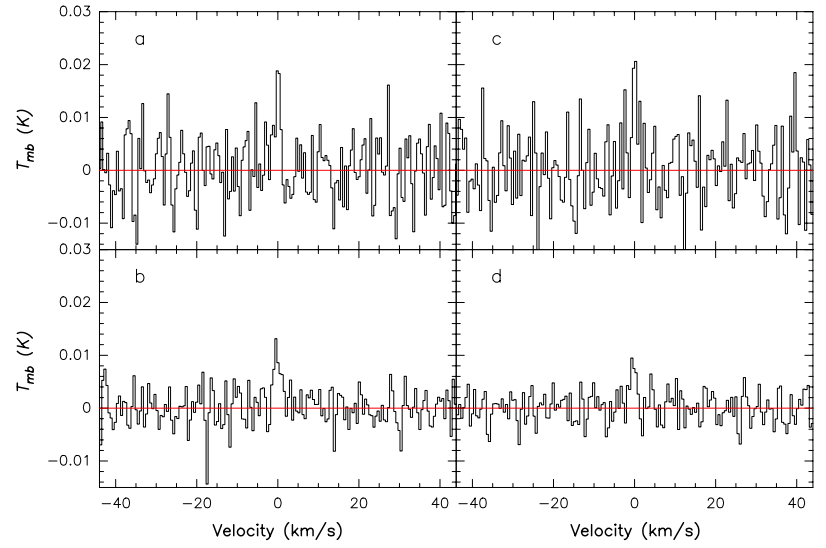

Fig. 2. Weighted average of the 5-10 strongest $\mathrm{NH}_{2} \mathrm{CHO} J(11-10)$ and $J$ (12-11) lines (Table 5). a) C/2012 F6 (Lemmon), 6-8 April 2013; b) C/2013 R1 (Lovejoy), 8-12 Nov. 2013; c) C/2013 R1 (Lovejoy), 27 Nov.-1 Dec. 2013; d) C/2013 R1 (Lovejoy), 9-16 Dec. 2013. Scales as in Fig. 1.

$165 \mathrm{GHz}$ methanol lines in comet Lovejoy agree within $3 \mathrm{~K}$. The gas expansion velocity (Table 1) is deduced from the line width of the strongest emission lines (e.g., HCN J(3-2), CS J(5-4) and some strong $\mathrm{CH}_{3} \mathrm{OH}$ lines).

Section 3.2 presents the detection of $\mathrm{HCOOH}$ and $\mathrm{CH}_{3} \mathrm{CHO}$ and searches for other $\mathrm{CHO}$-bearing molecules.

\subsection{Production rates of ethylene glycol and formamide}

The estimated production rates of ethylene glycol are given in Table 1. The predicted intensities of the ethylene glycol lines are very close to those expected for thermal equilibrium (the difference is lower than 1\%), so that the approximations used for the excitation of this molecule probably do not affect our estimates of the production rates significantly. The photodissociation rate at $1 \mathrm{AU}$ was assumed to be $\beta_{0}=2.0 \times 10^{-5} \mathrm{~s}^{-1}$ (Crovisier et al. 2004a). Multiplying it by 2 increases the derived production rates by $\approx 20 \%$ for Lemmon and $\approx 10 \%$ for Lovejoy.

The width and asymmetry of the ethylene glycol line detected in comet Lemmon (Fig. 1a) is comparable to that of the other species. The derived production rate is indicative of an abundance relative to water of $0.24 \%$.

Ethylene glycol was detected in comet Lovejoy during the second (27-31 Nov.) and third (9-16 Dec.) observing periods with average productions rates of $3.4 \pm 1.1 \times 10^{26}$ and
$3.4 \pm 0.6 \times 10^{26}$ molec. $\mathrm{s}^{-1}$, yielding abundances relative to water of $0.40 \pm 0.13 \%$ and $0.30 \pm 0.05 \%$. The marginal difference between the two periods might be due to, e.g., an underestimate of the gas temperature $T_{\text {kin }}$ when the comet was closer to Earth at the end of November. Using $T_{\text {kin }}=80 \mathrm{~K}$ instead of $65 \mathrm{~K}$, the derived abundance for late November is $0.36 \pm 0.11 \%$, and the differences between the production rates derived from the low- and high-frequency groups of lines (Table 2) are also reduced. On the other hand, we did not find any measurable variation $(>10 \%)$ of $T_{\text {kin }}$ in the coma, yielding an uncertainty lower than $5 \%$ on the production rate of ethylene glycol.

For the first observing period, we derive an upper limit of $0.62 \%$, which explains the non-detection.

The derived production rate of formamide strongly depends on the assumed photodissociation rate, which is presumably high $\left(\beta_{0}=7 \times 10^{-4} \mathrm{~s}^{-1}\right.$ according to Jackson 1976a,b). In this case, most molecules lie in the collision-dominated coma region, so that radiative processes do not play an important role in the rotational excitation of the molecule. Following Bockelée-Morvan et al. (2000), we investigated how the assumed photodissociation rate affects the derived production rate for comet Lovejoy and its evolution with time. Indeed, comet Lovejoy was observed over a range of heliocentric and geocentric distances (Table 1), which makes the evolution of the signal sensitive to the lifetime of formamide. Abundances relative to water for the three periods are $(7.2 \pm 5.0 ; 5.4 \pm 1.9 ; 7.3 \pm 2.5) \times 10^{-4}$, $(3.4 \pm 2.0 ; 2.2 \pm 0.6 ; 2.0 \pm 0.6) \times 10^{-4}$, and $(2.8 \pm 1.8 ; 1.7 \pm 0.5$; $1.3 \pm 0.4) \times 10^{-4}$ for $\beta_{0}=7.0,1.0$, and $0.1 \times 10^{-4} \mathrm{~s}^{-1}$, respectively. For $\beta_{0}=1.0 \times 10^{-5} \mathrm{~s}^{-1}$, the abundance of formamide decreases with time, while for $\beta_{0}=7.0 \times 10^{-4} \mathrm{~s}^{-1}$ the abundance increases from period 2 to 3 . This means that $\beta_{0}$ is more likely around $1.0 \times 10^{-4} \mathrm{~s}^{-1}$, which implies an abundance of formamide relative to water in Lovejoy of $0.021 \%$. The detection of formamide in comet Lemmon is marginal, but this value of $\beta_{0}$ yields a $\mathrm{NH}_{2} \mathrm{CHO} / \mathrm{H}_{2} \mathrm{O}$ ratio of $0.016 \pm 0.005 \%$, which is close to that found in comet Lovejoy and similar to the value measured in comet Hale-Bopp (Bockelée-Morvan et al. 2000). Production rates given in Table 2 are for $\beta_{0}=1.0 \times 10^{-4} \mathrm{~s}^{-1}$. A $10 \%$ variation of $T_{\text {kin }}$ would only modify the production rate of formamide in either comet by $3 \%$.

\subsection{Abundances of other complex molecules}

Using the method outlined in Sect. 3, we searched for a number of CHO-bearing molecules in the spectra of comets Lemmon and Lovejoy. Production rates, or upper limits, were determined 
Table 3. Abundances relative to water.

\begin{tabular}{|c|c|c|c|}
\hline \multirow[t]{2}{*}{ Molecule } & \multicolumn{3}{|c|}{ Abundance (\%) } \\
\hline & $\begin{array}{l}\text { C/1995 O1 }{ }^{a} \\
\text { (Hale-Bopp) }\end{array}$ & $\begin{array}{l}\text { C/2012 F6 } \\
\text { (Lemmon) }\end{array}$ & $\begin{array}{c}\text { C/2013 R1 } \\
\text { (Lovejoy) }\end{array}$ \\
\hline $\mathrm{HCN}$ & 0.25 & 0.14 & 0.16 \\
\hline $\mathrm{CO}$ & 23 & $4.0^{b}$ & $7.2^{c}$ \\
\hline $\mathrm{H}_{2} \mathrm{CO}$ & 1.1 & $0.7^{c}$ & $0.7^{c}$ \\
\hline $\mathrm{CH}_{3} \mathrm{OH}$ & 2.4 & 1.6 & 2.6 \\
\hline $\mathrm{HCOOH}$ & 0.09 & $<0.07$ & 0.12 \\
\hline$\left(\mathrm{CH}_{2} \mathrm{OH}\right)_{2}$ & 0.25 & 0.24 & 0.35 \\
\hline HNCO & 0.10 & $0.025^{c}$ & $0.021^{c}$ \\
\hline $\mathrm{NH}_{2} \mathrm{CHO}$ & 0.02 & 0.016 & 0.021 \\
\hline $\mathrm{HCOOCH}_{3}$ & 0.08 & $<0.16$ & $<0.20$ \\
\hline $\mathrm{CH}_{3} \mathrm{CHO}$ & 0.025 & $<0.07$ & 0.10 \\
\hline $\mathrm{CH}_{2} \mathrm{OHCHO}$ & $<0.04$ & $<0.08$ & $<0.07$ \\
\hline
\end{tabular}

Notes. ${ }^{(a)}$ Bockelée-Morvan et al. (2000); Crovisier et al. (2004a,b). ${ }^{(b)}$ Paganini et al. (2014). ${ }^{(c)}$ Biver et al., in prep.

assuming the local thermodynamical equilibrium, and the corresponding abundances relative to water are displayed in Table 3. Formic acid $(\mathrm{HCOOH})$ is detected in comet Lovejoy (more than 6 lines with a $S / N>3$ ), but not in comet Lemmon. Acetaldehyde $\left(\mathrm{CH}_{3} \mathrm{CHO}\right)$ is detected at the $4 \sigma$ level in comet Lovejoy, both at the end of November (average of 39 lines) and in December (45 lines) (Table 4). $\mathrm{CH}_{3} \mathrm{CHO}$ was previously detected only in comet Hale-Bopp before (Crovisier et al. 2004b). Methyl formate $\left(\mathrm{CH}_{3} \mathrm{OCHO}\right)$ and glycolaldehyde $\left(\mathrm{CH}_{2} \mathrm{OHCHO}\right)$ are not detected, but significant upper limits are obtained. Methyl formate and formic acid were detected in comet Hale-Bopp (Bockelée-Morvan et al. 2000; Crovisier et al. 2004b). We also include in Table 3 the abundances of HNCO and $\mathrm{H}_{2} \mathrm{CO}$ (Biver et al., in prep.).

\section{Discussion}

Chemical diversity is observed in the population of Oort Cloud comets, with abundances varying by up to a factor of ten for several simple species such as $\mathrm{CO}, \mathrm{CH}_{3} \mathrm{OH}, \mathrm{H}_{2} \mathrm{~S}, \mathrm{CS}$, and hydrocarbons (e.g., Bockelée-Morvan 2011). The origin of this diversity is unclear and might reflect comet formation at different places and times in the early solar system. The abundances of ethylene glycol and formamide in comets Lemmon and Lovejoy are remarkably similar to the values measured in comet HaleBopp (Table 3). Conversely, HNCO and CO are depleted by a factor of 4-5 in both comets with respect to Hale-Bopp, whereas $\mathrm{HCOOH}$ is depleted in comet Lemmon and not in Lovejoy, and acetaldehyde is enhanced in Lovejoy.

The comparison of cometary abundances with those measured around protostars can shed light on the processes responsible for the formation of complex molecules in protoplanetary disks. It is important to decipher the role of grain-surface chemistry and radiation processing versus gas-phase chemistry (Walsh et al. 2014). As discussed by Crovisier et al. (2004a) and Walsh et al. (2014), an important issue is the now confirmed high abundance of ethylene glycol in comets, which is at least 5-6 times higher than that of the chemically related species $\mathrm{CH}_{2} \mathrm{OHCHO}$ (glycolaldehyde) (Table 3). By contrast, both molecules are observed in similar abundances in the hot core Sgr B2(N) (Hollis et al. 2002), and tentatively in the Class 0 solar-type binary protostar IRAS 16293-2422, where ethylene glycol relative to glycolaldehyde is $0.3-0.5$ (Jørgensen et al. 2012). In IRAS 16293-2422, the glycolaldehyde lines have their origin in the warm (200-300 K) gas close to binary components (Jørgensen et al. 2012). Similarly, ethylene glycol, together with other complex molecules is found to originate from a warm region of radius $\sim 60 \mathrm{AU}$ in the Class 0 source NGC 1333-IRAS2a. Hence, this supports a scenario where these two molecules are released into the gas phase by the sublimation of grain mantles. From laboratory experiments, Öberg et al. (2009) showed that both molecules are produced by UV-irradiation of methanol ices mixed with $\mathrm{CO}$, with the amount of ethylene glycol relative to glycolaldehyde increasing with decreasing $\mathrm{CO}$ content and being sensitive to the temperature. This suggests that complex molecules found in cometary ices might have been formed from the irradiation of CO-poor ices. We note, however, that there is no correlation between the $\mathrm{CO}$ and ethylene glycol abundances in comets (Table 3 ).

Formamide, the simplest amide, may have been the starting point for prebiotic synthesis (Saladino et al. 2012). Formamide has recently been detected in the Class 0 source IRAS 162932422, with an abundance 10 times lower than the Hale-Bopp value (Kahane et al. 2013). Several formation routes are proposed for $\mathrm{NH}_{2} \mathrm{CHO}$ in protoplanetary disks (Kahane et al. 2013; Walsh et al. 2014). Grain-surface chemistry satisfactorily explains the $\mathrm{NH}_{2} \mathrm{CHO}$ abundance relative to water measured in cometary ices, as well as that of most $\mathrm{CHO}$-bearing species detected in comets (excluding ethylene glycol; Walsh et al. 2014).

In summary, the new measurements presented here show that the high abundance of ethylene glycol is most likely a specific property of comets. Molecules present in cometary ices could have formed by a wealth of chemical processes, which will hopefully be better constrained in the coming years by the combination of new observations, models, and laboratory works.

Acknowledgements. This research has been supported by the Programme national de planétologie de l'Institut des sciences de l'univers (INSU).

\section{References}

Agúndez, M., Biver, N., Santos-Sanz, P., et al. 2014, A\&A, 564, L2 Biver, N., Bockelée-Morvan, D., Crovisier, J., et al. 1999, AJ, 118, 1850 Biver, N., Bockelée-Morvan, D., Crovisier, J., et al. 2000, AJ, 120, 1554 Biver, N., Bockelée-Morvan, D., Colom, P., et al. 2011, A\&A, 528, A142 Biver, N., Bockelée-Morvan, D., Crovisier, J., et al. 2006, A\&A, 449, 1255 Biver, N., Debout V., Bockelée-Morvan, D., et al. 2013, AAS DPS meeting 45 , 502.03

Bockelée-Morvan, D. 2011, IAU Symp., 280, 261

Bockelée-Morvan, D., Lis, D.C., Wink, J. E., et al. 2000, A\&A, 353, 1101

Carter, M., Lazareff, R., Maier, D., et al. 2012, A\&A, 538, A89

Combi, M., Bertaux, J.-L., Quémerais, E., et al. 2014, AJ, 147, 126

Crovisier, J., Bockelée-Morvan, D., Biver, N., et al. 2004a, A\&A, 418, L35 Crovisier, J., Bockelée-Morvan, D., Colom, P., et al. 2004b, A\&A, 418, 1141 Hartogh, P., Lis, D.C., Bockelée-Morvan, D., et al. 2011, Nature, 478, 218 Hollis, J. M., Lovas, F. J., Jewell, P. R., \& Coudert, L. H. 2002, ApJ, 571, L59 Jackson, W. M. 1976a, In NASA Goddard space Fright Center, The Study of Comets, 393, 679

Jackson, W. M. 1976b, J. Photochem., 5, 107

Jørgensen, J. K., Favre, C., Bisschop, S. E., et al. 2012, ApJ, 757, L4 Kahane, C., Ceccarelli, C., Faure, A., \& Caux, E. 2013, ApJ, 763, L38 Lovejoy, T. 2013, Central Bureau Electronic Telegrams, 3649, 1

Müller, H. S. P., Schlöder, F., Stutzki, J., \& Winnewisser, G. 2005, J. Mol. Struct. 742,215

Öberg, K. I., Garrod, R. T., van Dishoeck, E. F., \& Linnartz, H. 2009, A\&A, 504, 891

Paganini, L., DiSanti, M. A., Mumma, M. J., et al. 2014, AJ, 147, 15

Saladino, R., Crestini, C., Pino, S., et al. 2012, Phys. Life Rev., 9, 84

Walsh, C., Millar, T. J., Nomura, H., et al. 2014, A\&A, 563, A33

Williams, G. V. 2014, Minor Planet Electronic Circ. 2014-E18 
Table 4. Observed lines and production of ethylene glycol.

\begin{tabular}{|c|c|c|c|c|c|c|c|c|c|c|c|c|c|}
\hline \multirow[t]{3}{*}{ Transition } & \multirow{3}{*}{$\begin{array}{c}\text { Frequency } \\
{[\mathrm{MHz}]}\end{array}$} & \multicolumn{3}{|c|}{ Lemmon 6-8 Apr. } & \multicolumn{3}{|c|}{ Lovejoy 8-12 Nov. } & \multicolumn{3}{|c|}{ Lovejoy 27-31 Nov. } & \multicolumn{3}{|c|}{ Lovejoy 9-16 Dec. } \\
\hline & & [mK kr & & & & & & & & & {$[\mathrm{mK} \mathrm{kı}$} & $\left.\mathrm{n} \mathrm{s}^{-1}\right]^{a}$ & \\
\hline & & Model $^{b}$ & Obs. & {$\left[10^{26} \mathrm{~s}^{-1}\right]$} & Model $^{c}$ & Obs. & {$\left[10^{26} \mathrm{~s}^{-1}\right]$} & Model $^{c}$ & Obs. & {$\left[10^{26} \mathrm{~s}^{-1}\right]$} & Model $^{c}$ & Obs. & {$\left[10^{26} \mathrm{~s}^{-1}\right]$} \\
\hline $\begin{array}{l}22_{1,22,1}-21_{1,21,0} \\
22_{0,22,1}-21_{0,21,0}\end{array}$ & $\begin{array}{l}213131.96 \\
213132.92\end{array}$ & & & & 47.5 & & & 40.5 & & & 25.2 & & \\
\hline $\begin{array}{l}24_{1,24,0}-23_{1,23,1} \\
24_{0,24,0}-23_{0,23,1}\end{array}$ & $\begin{array}{l}217449.99 \\
217450.27\end{array}$ & & & & 37.0 & & & 33.6 & & & 22.1 & & \\
\hline $\begin{array}{l}23_{1,23,1}-22_{1,22,0} \\
23_{0,23,1}-22_{0,22,0}\end{array}$ & $\begin{array}{l}222348.60 \\
222349.15\end{array}$ & & & & 44.6 & & & & & & 25.2 & & \\
\hline $\begin{array}{l}25_{1,25,0}-24_{1,24,1} \\
25_{0,25,0}-24_{0,24,1}\end{array}$ & $\begin{array}{l}226643.30 \\
226643.46\end{array}$ & & & & 34.1 & $<42$ & $<5.3$ & 32.0 & $18 \pm 6$ & $2.5 \pm 0.8$ & 21.8 & $18 \pm 4$ & $3.8 \pm 0.8$ \\
\hline $\begin{array}{l}24_{3,22,0}-23_{3,21,1} \\
22_{4,19,1}-21_{4,18,0}\end{array}$ & $\begin{array}{l}230577.15 \\
230578.26\end{array}$ & & & & 36.7 & & & 33.8 & & & 22.7 & & \\
\hline $\begin{array}{l}24_{1,24,1}-23_{1,23,0} \\
24_{0,24,1}-23_{0,23,0}\end{array}$ & $\begin{array}{l}231564.01 \\
231564.32\end{array}$ & & & & 41.2 & & & 37.5 & & & 24.7 & & \\
\hline $\begin{array}{l}25_{1,25,1}-24_{1,24,0} \\
25_{0,25,1}-24_{0,24,0}\end{array}$ & $\begin{array}{l}240778.13 \\
240778.30\end{array}$ & 39.0 & & & 37.9 & & & 35.7 & & & 24.4 & & \\
\hline $\begin{array}{l}27_{1,27,0}-26_{1,26,1} \\
27_{0,27,0}-26_{0,26,1}\end{array}$ & $\begin{array}{l}245022.74 \\
245022.79\end{array}$ & 34.7 & & & 27.6 & & & 28.6 & & & 21.3 & & \\
\hline $\begin{array}{l}26_{1,26,1}-25_{1,25,0} \\
26_{0,26,1}-25_{0,25,0}\end{array}$ & $\begin{array}{l}249990.90 \\
249991.00\end{array}$ & 37.4 & & & 34.1 & & & 34.3 & & & 24.7 & & \\
\hline $\begin{array}{l}25_{3,23,1}-24_{3,22,0} \\
24_{5,20,1}-23_{5,19,0}\end{array}$ & $\begin{array}{l}253616.77 \\
253618.60\end{array}$ & 34.8 & & & & & & & & & & & \\
\hline $\begin{array}{l}28_{1,28,0}-27_{1,27,1} \\
28_{0,28,0}-27_{0,27,1}\end{array}$ & $\begin{array}{l}254208.72 \\
254208.75\end{array}$ & 32.7 & $39 \pm 5$ & $22 \pm 3$ & 24.2 & $<21$ & $<3.9$ & 26.0 & $23 \pm 4$ & $4.0 \pm 0.7$ & 20.1 & $13 \pm 4$ & $3.0 \pm 0.9$ \\
\hline $\begin{array}{l}27_{1,27,1}-26_{1,26,0} \\
27_{0,27,1}-26_{0,26,0}\end{array}$ & $\begin{array}{l}259202.27 \\
259202.32\end{array}$ & 38.6 & & & 29.9 & & & 31.1 & & & 23.1 & & \\
\hline $\begin{array}{l}29_{1,29,0}-28_{1,28,1} \\
29_{0,29,0}-28_{0,28,1}\end{array}$ & $\begin{array}{l}263392.10 \\
263392.12\end{array}$ & 32.9 & & & 20.8 & & & 23.1 & & & 18.5 & & \\
\hline $\begin{array}{l}28_{1,28,1}-27_{1,27,0} \\
28_{0,28,1}-27_{0,27,0}\end{array}$ & $\begin{array}{l}268412.15 \\
268412.18\end{array}$ & 35.8 & & & 26.2 & & & 29.9 & & & 21.7 & & \\
\hline $\begin{array}{l}29_{2,28,0}-28_{2,27,1} \\
29_{1,28,0}-28_{1,27,1} \\
\end{array}$ & $\begin{array}{l}269941.61 \\
269942.57 \\
\end{array}$ & 30.1 & & & & & & & & & & & \\
\hline
\end{tabular}

Notes. Frequencies are from the Cologne Database for Molecular Spectroscopy (Müller et al. 2005). ${ }^{(a)}$ Line integrated intensity $\int T_{m b} \mathrm{~d} v{ }^{\left({ }^{(b)}\right.}$ model with $Q_{\mathrm{glycol}}=2 \times 10^{27}$ molec. $\mathrm{s}^{-1}{ }^{\left({ }^{(c)}\right.}$ model with $Q_{\mathrm{glycol}}=5 \times 10^{26}$ molec. $\mathrm{s}^{-1}$.

Table 5. Observed lines and production rate of formamide.

\begin{tabular}{|c|c|c|c|c|c|c|c|c|c|c|c|c|c|}
\hline \multirow[t]{2}{*}{ Transition } & \multirow{2}{*}{$\begin{array}{c}\text { Frequency } \\
{[\mathrm{MHz}]}\end{array}$} & \multicolumn{3}{|c|}{ Lemmon 6-8 Apr. } & \multicolumn{3}{|c|}{ Lovejoy 8-12 Nov. } & \multicolumn{3}{|c|}{ Lovejoy 27-31 Nov. } & \multicolumn{3}{|c|}{ Lovejoy 9-16 Dec. } \\
\hline & & $\begin{array}{r}{[\mathrm{mK} \mathrm{k1}} \\
\text { Model }^{a} \\
\end{array}$ & $\begin{array}{l}\left.\mathrm{n} \mathrm{s}^{-1}\right]^{a} \\
\text { Obs. }\end{array}$ & $\begin{array}{c}Q \\
{\left[10^{25} \mathrm{~s}^{-1}\right]}\end{array}$ & $\begin{array}{r}{[\mathrm{mK} \text { kn }} \\
\text { Model }^{a} \\
\end{array}$ & $\begin{array}{l}\left.\mathrm{m} \mathrm{s}^{-1}\right]^{a} \\
\text { Obs. }\end{array}$ & $\begin{array}{c}Q \\
{\left[10^{25} \mathrm{~s}^{-1}\right]} \\
\end{array}$ & $\begin{array}{r}{[\mathrm{mK} \mathrm{k}} \\
\text { Model }^{a} \\
\end{array}$ & $\begin{array}{l}\left.\mathrm{m} \mathrm{s}^{-1}\right]^{a} \\
\text { Obs. }\end{array}$ & $\begin{array}{c}Q \\
{\left[10^{25} \mathrm{~s}^{-1}\right]}\end{array}$ & $\begin{array}{r}{[\mathrm{mK} \mathrm{kr}} \\
\text { Model }^{a} \\
\end{array}$ & $\begin{array}{c}\left.\mathrm{m} \mathrm{s}^{-1}\right]^{a} \\
\text { Obs. }\end{array}$ & $\begin{array}{c}Q \\
{\left[10^{25} \mathrm{~s}^{-1}\right]} \\
\end{array}$ \\
\hline $\begin{array}{l}11_{1,11}-10_{1,10} \\
11_{0,11}-10_{0,10} \\
11_{2,10}-10_{2,9} \\
11_{2,9}-10_{2,8} \\
11_{1,10}-10_{1,9}\end{array}$ & $\begin{array}{l}223452.51 \\
227605.66 \\
232273.65 \\
237896.68 \\
239951.80\end{array}$ & & & & $\begin{array}{l}161.2 \\
151.7 \\
134.4 \\
139.9 \\
164.1\end{array}$ & $<32$ & $<6.4$ & 111.2 & $38 \pm 12$ & $3.2 \pm 1.0$ & $\begin{array}{l}53.8 \\
56.9 \\
51.7 \\
54.4 \\
60.8\end{array}$ & $17 \pm 5$ & $3.0 \pm 0.9$ \\
\hline $\begin{array}{l}12_{1,12}-11_{1,11} \\
12_{0,12}-11_{0,11} \\
12_{2,11}-11_{2,10} \\
12_{2,10}-11_{2,9} \\
12_{1,11}-11_{1,10}\end{array}$ & $\begin{array}{l}243521.04 \\
247390.72 \\
253165.79 \\
260189.09 \\
261327.45\end{array}$ & $\begin{array}{l}16.7 \\
17.4 \\
15.7 \\
17.1 \\
18.7\end{array}$ & $24 \pm 7$ & $14 \pm 4$ & $\begin{array}{l}163.8 \\
136.7 \\
140.8 \\
164.0\end{array}$ & $34 \pm 8$ & $2.2 \pm 0.5$ & $\begin{array}{l}124.2 \\
129.8 \\
112.6 \\
116.5 \\
132.6\end{array}$ & $21 \pm 4$ & $1.7 \pm 0.3$ & $\begin{array}{l}65.6 \\
68.3 \\
61.9 \\
64.3 \\
71.5\end{array}$ & $16 \pm 5$ & $2.4 \pm 0.7$ \\
\hline $\begin{array}{l}13_{1,13}-12_{1,12} \\
13_{0,13}-12_{0,12}\end{array}$ & $\begin{array}{l}263542.24 \\
267062.61\end{array}$ & $\begin{array}{l}19.2 \\
19.0\end{array}$ & $<54$ & $<28$ & $\begin{array}{l}156.9 \\
165.5\end{array}$ & $<42$ & $<2.6$ & $\begin{array}{l}127.2 \\
133.7\end{array}$ & $22 \pm 8$ & $1.7 \pm 0.6$ & $\begin{array}{l}69.9 \\
73.3\end{array}$ & $<24$ & $<3.4$ \\
\hline
\end{tabular}

Notes. ${ }^{(a)}$ Line intensities modelled with $Q_{\mathrm{NH}_{2} \mathrm{CHO}}=10^{26}$ molec. $\mathrm{s}^{-1}$ and photodissociation rates at 1 AU $\beta_{0}=1 \times 10^{-4} \mathrm{~s}^{-1}$. 